\title{
Heróis na janela
}

\author{
Lucia Santa Cruz ${ }^{1}$ \\ UFRJ \\ luciasantacruz@gmail.com
}

\begin{abstract}
Resumo: Este artigo pretende discutir se é possível afirmarmos que programas jornalísticos de televisão que elegem como pauta principal o tema da Responsabilidade Social Empresarial se situam dentro do gênero narrativo. Esta hipótese surge da percepção que estes programas, enquanto práticas comunicativas, além de incorporarem elementos próprios da narrativa, como o relato de ações que se desenrolam sobre uma linha temporal, tendem a heroicizar personagens de suas reportagens e a relatar fatos como epopéias ou conquistas de indivíduos ou eventualmente de grupos, valendo-se para isso dos recursos técnicos e de linguagem do meio televisivo.
\end{abstract}

Palavras-Chave: Jornalismo 1. Responsabilidade social 2. Televisão 3. Narrativa jornalística 4.

Abstract: This article intends to argue if its possible to affirm that journalistic television shows which main subject is the corporate social responsibility can be classified as narrative gender. This hypothesis appears of the perception that these programs, while communicative practices, beyond incorporating proper elements of the narrative (like the story organized as a timeline), tend to heroicize the caracters of the story and to tell facts as epics or conquests of individuals or more rarely, of groups, using technical resources and television language.

Main words: Journalism 1. Social Responsibility 2. Television 3. Journalistic Narrative

${ }^{1}$ Doutoranda em Comunicação e Cultura, Mestre em Comunicação e Cultura, UFRJ, Professora substituta da Escola de Comunicação da UFRJ 
Extracto: Este artículo se prepone discutir si es posible afirmar que los productos periodísticos de la televisión cuyo tema principal es la responsabilidad social corporativa se puedan clasificar como género narrativo. Esta hipótesis aparece de la opinión que estos programas, mientras que las prácticas comunicativas, más allá de incorporar los elementos apropiados de la narrativa (como la historia organizada como timeline), tienden a heroicize los personages de la historia y narrar hechos como las epopeyas o conquistas de individuos o más raramente, de grupos, usando recursos y lengua técnicos de la televisión

Palabras principales: Periodismo 1. Responsabilidad social 2. Televisión 3. Narrativa periodística

Abrégé: Cet article prévoit pour discuter si c'est possible d'affirmer que des programmes journalistiques de télévision dont le sujet principal est la Responsabilité Sociale d'Entrepriseem peuvent être classifiées en tant que genre narratif. Cette hypothèse est évident de la perception que ces programmes, alors que les pratiques communicatives, au delà d'incorporer les éléments appropriés du récit (comme l'histoire organisée comme chronologie), tendent a heroicize les personnages de l'histoire et pour raconter des faits comme épopées ou conquêtes des individus ou, plus rarement, des groupes, en utilisant les ressources et la langue techniques de télévision.

Mots principaux: Journalisme 1. Responsabilité sociale d'entreprise 2. Télévision 3. Récit journalistique. 


\section{Janelas e molduras}

Uma televisão instalada num restaurante a quilo é uma janela. Por ela, o cliente que mistura feijão e sushi, farofa e estrogonofe num único prato se permite apreciar a paisagem. Na maioria das vezes solitário, se debruça na janela da tv e acredita contemplar o mundo. A força imagética é tão intensa que muitos destes aparelhos estão com o áudio desligado. Sem som, mas com o poder da imagem em movimento. Pela janela, se descortina a vida.

Janela para uns, vitrine para outros. Em ambos os casos, movimentos de olhar, ser olhado, conhecer e reconhecer. Veículo de maior audiência no Brasil, embora o rádio ainda detenha o posto de mídia com maior cobertura geográfica, a televisão está presente em $91,4 \%$ dos domicílios brasileiros. ${ }^{2}$ Este alcance massivo faz com que a mídia televisiva seja um espaço de reconhecimento e de construção da identidade nacional, mesmo quando retrata rostos distantes de algumas realidades regionais. "Para o telespectador, a fascinação está no mero olhar, na visão familiar de um mundo que se 'presentifica' ao se girar o botão do aparelho-receptor", lembra Muniz Sodré (2001:72), para quem a televisão é um eletrodoméstico, ou seja, um aparelho que se integra às necessidades domésticas do cotidiano..

A televisão é também a moldura dentro da qual são narradas histórias e são elaborados enredos. Se pensarmos que dentro dos contornos físicos da tela cabem movimentos que contam vidas, vamos nos deparar com um aspecto peculiar - a mídia televisiva constrói narrativas, no sentido que Mieke Bal deu à expressão.

un texto narrativo será aquel em que un agente relate una historia. Una historia es una fábula presentada de cierta manera. Una fabula es una serie de acontecimientos lógica y cronologicamente relacionados que unos actores causan o experimentan. Un acontecimento es la transición de un estado a otro. Los actores son agentes que llevan a cabo acciones. No son necessariamente

\footnotetext{
${ }^{2}$ De acordo com a Pesquisa Nacional por Amostra de Domiciliar de 2005, executada pelo IBGE, do total das moradias do País, $88,0 \%$ tinham geladeira, $16,7 \%$ possuíam freezer e $35,8 \%$ contavam com máquina de lavar roupa. A televisão existia em $91,4 \%$ dos domicílios e o rádio em $88,0 \%$, enquanto o microcomputador estava disponível em $18,6 \%$ das residências. Constatou-se, ainda, que em 13,7\% dos domicílios havia microcomputador com acesso à Internet.
} 
humanos. Actuar se define aqui como causar o experimentar un acontecimiento. (BAL, apud CONTURSI \& FERRO, 2000, p. 12)

Estas narrativas - este "ver a vida passar pela janela" - estão muito além da ficção, das telenovelas, dos filmes e seriados. A narrativa de que falamos neste artigo se encontra nos programas jornalísticos, nos quais as notícias se apresentam como relatos do real, crônicas do cotidiano, observação dos acontecimentos.

O jornalismo se impõe, da maneira angular, como possibilidade dos indivíduos em participar do mundo mediato pela via de sua feição dinâmica e singular, como algo sempre incompleto, atribuindo significações e totalizando de maneira permanente como se estivessem vivendo na imediaticidade de sua aldeia (GENRO, 1987, p. 59)

\section{Jornalismo como narrativa}

Alguns autores contemporâneos, como Raquel Paiva, pretendem que o jornalismo é narrativa por si mesmo. A autora trabalha com a pressuposição que o relato jornalístico seria, por sua natureza, a narrativa da atualidade, sendo que sua estrutura narrativa estaria dada no seu próprio fazer, na sua própria existência, na qual conteria a condição de narrativa. "Esta é a hipótese que se pretende demonstrar tomando como metodologia os instrumentos da prática jornalística, sejam pauta, apuração, produção. É na seqüencialidade da sua produção que a narrativa se apresenta e existe”.(PAIVA, 2006, p. 67)

A discussão sobre se o jornalismo é um relato fiel e objetivo da realidade factual soa ultrapassada. O jornalismo e seus produtos não são verdadeiros - são críveis, isto é, estabelecem com seus leitores um acordo - o chamado pacto ficcional, que é um princípio que diz que o leitor deve dar crédito de realidade à ficção, ao relato, por mais fantástico e abstrato que se apresente. O fazer jornalístico é uma tentativa de representação e não de transcrição, é uma forma de contar os fatos. O jornalismo é uma leitura sobre o mundo, não do mundo. É um olhar construído

\footnotetext{
3 "Um texto narrativo será aquele em que um agente relate uma historia. Uma historia é una fábula apresentada de certa maneira. Uma fábula é uma série de acontecimentos lógica e cronologicamente relacionados que uns atores causam ou experimentam. Um acontecimento é a transição de um estado a outro. Os atores são agentes que levam a cabo ações. Não são necessariamente humanos. Atuar se define aqui como causar ou experimentar um acontecimento" - tradução livre. (BAL, apud CONTURSI \& FERRO, 2000, p.12
} 
historicamente por força de rotinas produtivas, transformações sociais, culturais e ideológicas, relações e interesses comerciais, políticos, etc. "Notícia é um produto cultural cuja magnitude vai além do ato de informar, situando o indivíduo na complexa sociedade contemporânea" (MOTTA, 2002, p. 12)

Pois é justamente esta construção histórica que assegura ao jornalismo um lugar definitivo como formulador da narrativa universal do 'atual' em nossa civilização, como ressalta Raquel Paiva.

Essa narrativa, quotidianamente composta, é tecida por critérios e postulados paradigmáticos que tentam definir de um modo bastante amplo o perfil da atualidade. Desta maneira, a partir de uma detida análise da produção jornalística podemos não apenas saber o que de presumidamente importante acontece, mas também porque e como assume este patamar o fato histórico que acontece no nosso dia-adia. Para o bem e para o mal, esse lugar alcançado pelo jornalismo define quem somos - e não apenas por meio daqueles que produzem a informação jornalística, mas basicamente por meio de todos os participantes desse processo, ou seja, seus meros consumidores. (PAIVA, 2006, p. 62)

\section{Movimento empresarial}

Ao considerarmos que o jornalismo é portanto um produto cultural, no sentido de produção de sentidos e significados por um grupo social, temos que atentar para os movimentos que perpassam a sociedade atualmente e são espelhados, retratados, realimentados pelos veículos jornalísticos. Este é o caso do crescente movimento da responsabilidade social empresarial, um conjunto de atividades desenvolvidas por empresas de todos os portes e setores, articulados em direção a uma intervenção no tecido social, para além de sua produção econômica. Embora ações isoladas de filantropia, caridade e marketing existam desde o início do século $\mathrm{XX}$, é nas últimas duas décadas que o movimento ganha força como ferramenta de gestão empresarial e assume posição estratégia nas corporações, sendo que a partir de 2000 a mídia constituí veículos específicos para tratar o tema, antes circunscrito a publicações corporativas.

Nos programas jornalísticos de televisão sobre o tema da responsabilidade social empresarial encontramos comprovações de que o jornalismo se estabelece como um relato narrativo da contemporaneidade. Atualmente no ar contabilizamos três programas semanais, com duração média de 30 minutos (incluindo breaks 
comerciais): na TVE temos o Mobilização Brasil (Sábados, às 8 h, transmitido por todas as emissoras educativas do país, em rede, com apresentação do jornalista Marco Piva), na TV Cultura, o Balanço Social (vai ao ar aos sábados, às 8h3omin, apresentado pela jornalista Alessandra Calor e com entrevistas no estúdio conduzidas pelo também jornalista Heródoto Barbeiro) e na TV Globo, o Ação (transmissão aos sábados, às 7h3omin, apresentado pelo jornalista Sérgio Groissman).

Estes programas, que surgem a partir do início do século, apresentam de maneira jornalística relatos de ações empresariais voltadas para questões sociais. Todos mesclam entrevistas no estúdio com reportagens que são relatos de casos: pequenas histórias que apresentam um projeto e contam as trajetórias de seus participantes, que passam a adquirir um status de personagens. O tema da responsabilidade social empresarial não se esgota nestes exemplos, pois encontramos reportagens sobre o assunto em vários outros programas, desde os noticiosos clássicos, passando pelos documentários, debates, mesas-redondas, painéis, talk shows, etc.

Conforme nos lembra Paiva, os conteúdos da comunicação podem ser organizados como discursos - descrições de um conteúdo sem personagens e de maneira não narrativa - ou como histórias, narrações nas quais os fatos são organizados segundo uma ordem cronológica ou causal e atribuídos a personagens.

Como analisou Todorov, ao tratar da narrativa literária, o texto jornalístico também é ao mesmo tempo história, por evocar uma certa realidade, e discurso, pela presença de um narrador que conta a história, e que tem diante dele um leitor: não são os acontecimentos relatados que contam, mas a maneira pela qual o narrador nos faz conhecê-los. (PAIVA et alli, 2004, p. 67)

O que importa é a maneira como o narrador coloca ao conhecimento do destinatário os feitos e os personagens narrados. Existe um narrador que relata uma história e um destinatário da mesma. Como o narrador é quem vai, na verdade, costurar os fatos, organizar a entrada em cena de cada elemento, reger o suspense, medir o clímax, está em suas mãos dirigir a narrativa. É desta forma que chegamos a considerar que a narrativa pode ser usada para exercer o controle social. "Las narrativas em el discurso publico pueden concernir tanto a la auto-legitimación como 
a la redifusión de la información que ellas contienen ${ }^{4}$, diz Barbie Zelizer, em seu ensaio sobre o tratamento dado pelos jornalistas norte-americanos à morte de Lee Harvey Oswald, apontado como assassino do Presidente John Kennedy. (apud Contursi \& Ferro, 2000, p. 98)

Na narrativa clássica, o que integra os relatos não é a linearidade, mas o pano de fundo do enredo. De acordo com Ford \& Longo, citamos por Contursi \& Ferro, o uso de casos (relatos de ocorrências, de fatos ${ }^{5}$ ) em meios de massa correspondem à narração de um acontecimento em termos individuais ou microsociais. Os fatos, porém, são sempre uma reconstrução, não um retrato da realidade. A transmissão dos acontecimentos nunca é lisa, há uma série de nuances que se interpõe neste processo - desde o repertório próprio e individual do emissor, passando pela natureza do veículo, por questões políticas, sociais, econômicas, etc. Por sua vez, o caso se inscreve em uma série (casuística), em um conjunto de casos que cobra valor da agenda dos meios em relação com a sua noticiabilidade e que somente tem coerência a partir de sua ligação, explícita e ad hoc. Os casos nos meios de massa remetem parcial ou aleatoriamente a leis ou normas, ao contrário do que acontece com a casuística na jurisprudência ou mesmo em outras ciências, de onde conforma ou pode conformar normativos. Podemos considerar portanto que o enredo que perpassa a produção destes programas de responsabilidade social empresarial é a superação que cada indivíduo em situação de exclusão social pode fazer a partir do apoio da iniciativa privada. defesa da participação mais ativa da empresa em projetos de cunho social, à revelia do Estado e das políticas públicas.

\section{Apresentação de heróis e heróinas}

Considerando que a televisão é uma janela, por onde se pode ver e ser visto, os programas televisivos sobre responsabilidade social empresarial abusam deste

\footnotetext{
${ }^{4}$ Em tradução livre: As narrativas no discurso público podem interessar tanto à autolegitimação quanto à redifusão da informação que elas contêm".

${ }^{5}$ No artigo Sobre o fato e o acontecimento (2005), Muniz Sodré e Raquel Paiva demonstram que o caso é aquilo que ocorre e, neste sentido, se assemelha a fato.
} 
conceito para tratar a pauta. Em vários deles, a tela faz parte do cenário e ela se abre para o telespectador, no mesmo movimento de quem se aproxima de uma janela para se debruçar e olhar "o lá de fora”. O próprio apresentador convida o espectador a ver por aquela janela que se abre a partir da janela-televisão. Como se o narrador estivesse apertando o botão do canal de televisão para o receptor - Eu estou olhando, olhe você também para este programa, vale a pena. Vamos ser testemunhas do olhar. O narrador, e a sua posição, comandam a narração, direcionam a abertura da janela.

O que está fora é que o não está no estúdio. E a paisagem que se descortina enquadra heróis. Pessoas que venceram suas dificuldades, com o apoio das iniciativas empresariais, e apresentam na tela suas trajetórias, verdadeiras epopéias, narradas muitas vezes na primeira pessoa, sem a aparente interferência de um repórter ou interlocutor. Herói é uma figura arquetípica que reúne em si os atributos necessários para superar de forma excepcional um determinado problema de dimensão épica. Difere-se de indivíduos comuns pela sua capacidade de realizar proezas que exigem a abundância de alguma virtude crucial aos seus objetivos - fé, coragem, vaidade, orgulho, força de vontade, determinação, paciência, etc.

Os heróis fazem jornadas difíceis, confrontam dragões ou outras criaturas mitológicas, descobrem tesouros perdidos, e mudam a natureza do mundo com seus atos singulares de coragem e de desprendimento. São figuras legendárias, dotadas com força ou habilidade grande, que ousam atender ao chamado da aventura. Joseph Campell, em seu livro O herói de mil faces, aponta para a existência de características básicas encontráveis na trajetória de qualquer herói. Primeiro, ele é introduzido em seu mundo ordinário, onde recebe o chamado para se aventurar. É relutante no início mas é incentivado pelo homem ou pela mulher velha sábia para cruzar o primeiro ponto inicial, onde encontra testes e ajudantes. Alcança a caverna mais interna, onde está sua prova mais dura. Apreende a espada ou o tesouro e é perseguido na estrada para voltar a seu mundo. Ressurge e é transformado por sua experiência. Retorna a seu mundo ordinário com um tesouro, um favor, ou um elixir para beneficiar seu mundo.

A opção pelo recurso narrativo do herói no jornalismo não é nem estranha nem inovadora. Fraser Bond, citado por Adelmo Genro, diz que um dos elementos de interesse da notícia é o culto do herói e da fama. Numa época nitidamente marcada 
por um jornalismo que cultua as celebridades - figuras de fama instantânea e fugaz a utilização do herói é uma maneira de atrair o telespectador. Contursi \& Ferro (2000) sinalizam que um texto narrativo deve ter como referente um acontecimento ou uma ação que cumpram com o critério de suscitar o interesse. Muniz Sodré destaca que questões técnicas específicas do meio colaboram para que o tratamento da televisão seja individualizado. "Há lugar para poucas pessoas no vídeo. Assim, as ações possíveis (inclusive as dramáticas) são aquelas que exploram, em primeiro lugar, a personalidade individual, colocando a ação de grupo como subordinada" (2001, p.75). Isto explica o uso intenso de closes e o recurso de o entrevistado falar diretamente para a câmera, como se seu interlocutor não fosse um jornalista, que está atrás das câmeras, mas sim o espectador, que o assiste do outro lado da "janela".

A construção destes heróis na tela da TV se dá também a partir do pacto ficcional que o leitor de todo texto narrativo firma com o autor, como ressalta Umberto Eco (apud Contursi \& Ferro, 2000). Chamamos aqui de texto narrativo qualquer narração, seja ela oral, escrita ou audiovisual, como é o caso dos programas televisivos. De fato, o receptor, ao se colocar defronte da narração, aceita suspender sua incredulidade, conferindo à narrativa um caráter de realidade.

O herói é uma figura mítica, e o mito em si já é uma narrativa, que remete ao passado ao mesmo tempo que conserva no presente as condições de explicar a realidade. Os heróis que estes programas televisivos retratam são assim. Eles superam suas dificuldades - o drama épico da pobreza, da miséria, do anafalbetismo, da exclusão - com o apoio providencial de alguma iniciativa empresarial. Tomemos como exemplo o relato que o programa Ação da TV Globo faz de um grupo de dança de Belo Horizonte, formado por jovens da periferia da capital mineira, o Balé de Rua, exibido no dia 16 de setembro de 2006. O apresentador do programa, Serginho Groissman, em long shot (plano aberto), descreve, em tom informal, um pouco do projeto, e encerra dizendo: "Mas antes de conversar com eles, vamos conhecer um pouco da história”. A partir daí, mesclando imagens de apresentações e danças do grupo com depoimentos dos integrantes, vai traçando o retrato mítico destes "heróis". O primeiro passo é mostrar as profissões que os bailarinos exerciam antes de ingressarem no grupo. Em seguida, cada um conta como foi chamado a participar do Balé de Rua, narrando também suas dificuldades iniciais. Serginho Groissman 
corta este bloco de depoimentos para uma entrevista, no estúdio, com um dos responsáveis pelo projeto, que ratifica o caráter de superação, acrescenta que muitos dos bailarinos, depois de se profissionalizarem, se tornaram instrutores voluntários de outros jovens em situação de risco como eles Para exemplificar, o programa mostra o cotidiano de um dos dançarinos, num tom elogioso, destacando as dificuldades no deslocamento de casa para o trabalho, sua dedicação, as horas dedicadas ao trabalho voluntário, etc. O herói que superou sua dificuldade individual agora leva o segredo da superação aos outros de sua comunidade.

Partindo da análise que Bakhtin fez em Estética da Criação Verbal sobre a relação entre o autor e a personagem, podemos considerar que esta elaboração do herói nos programas de responsabilidade social empresarial segue o mesmo padrão que ocorre na obra literária. Muitos dos depoimentos dos "heróis populares" destes programas são pontuados por observações do apresentador (que faz as vezes de narrador), que ratificam e conformam suas declarações. A própria montagem das entrevistas e a sequência dos depoimentos reforçam esta condição. O jogo entre estúdio e reportagem, que alterna a entrevista com o responsável pelo projeto (em geral alguém que não é da mesma classe social/grupamento/coletividade/comunidade do herói retratado) com as falas diretas dos indivíduos, em close e no campo, também pontua a edição, conduzindo o olhar do espectador para fixar melhor determinados aspectos da "vista de sua janela".

A consciência da personagem, seu sentimento e seu desejo de mundo - diretriz volitivo-emocional concreta - é abrangida de todos os lados, como em um círculo, pela consciência concludente do autor a respeito dele e do seu mundo; as afirmações do autor sobre a personagem abrangem e penetram as afirmações da personagem sobre si mesma. (BAKHTIN, 2003, p.11)

A ação de herói aqui nos é relatada não pelo narrador clássico, mas pelo narrador pós-moderno, aquele que, no entendimento de Silviano Santiago, quer extrair de si a ação narrada. "Ele narra a ação enquanto espetáculo a que se assiste (literalmente ou não) da platéia, da arquibancada ou de uma poltrona na sala de estar ou na biblioteca; ele não narra enquanto atuante" (SANTIAGO, 1989, p. 39). O narrador clássico era alguém que tinha vivido aquilo que contava - sua legitimidade e sua autoridade vinham essencialmente da sua experiência. Já o narrador pósmoderno conta o que viu, relata aquilo de que não participou. 


\section{Empresas na liderança}

Se o narrador não mais experimenta o que narra, quem passa a ser atuante, neste sentido, são os heróis apresentados na tela. Mas eles não estão sozinhos: ao seu lado, no desenrolar da narrativa, transparecem as empresas que patrocinam os programas e projetos de responsabilidade social empresarial, que ganham papéis principais. Os retratados, portanto, só são agentes porque impulsionados pela mão da empresa. Ou seja, a partir do momento em que são beneficiados por algum programa desta natureza, aqueles indivíduos assumem a condição heróica de superação das suas dificuldades e de suas comunidades.

As empresas, ao definirem para quem vão direcionar suas atividades de responsabilidade social, estabelecem uma determinada representação de grupos sociais, comunidades, faixas etárias, etc. Há, desta forma, aqui, uma representação de quem, dentre a população brasileira, é elegível a este tipo de programa. A principal característica que franqueia a elegibilidade para um projeto de responsabilidade social empresarial é a exclusão social - um outro nome para a pobreza. A pobreza caracterizada a priori como condição de sofrimento, como grau de inferioridade social. A situação miserável de grandes parcelas da população brasileira é um forte argumento arregimentado pelas empresas que defendem as práticas de responsabilidade social empresarial, funcionando como justificativa para estas ações de intervenção na sociedade.

Quando os produtos jornalísticos se interessam por narrar estes projetos, é a representação midiática do sofrimento dessa exclusão social que eles focam. Isso pode implicar na vitimização de parcelas da sociedade que necessitam de um resgate - ou uma "cura" que passa a ser representada pela ação social da empresa. Ou seja, antes de individualizados como heróis (e logo, como representantes únicos de determinados grupamentos, que desempenham feitos memoráveis e extraordinários) os retratados nos programas são enquadrados como vítimas - prontos para serem imolados e ressurgirem como protagonistas de suas histórias.

Podemos aplicar este raciocínio também a outro exemplo, o programa Mobilização Brasil, da TVE, que foi ao ar no dia 14 de outubro de 2006, com a pauta do Desenvolvimento Regional Sustentável. O programa, que é produzido em parceria 
com a Fundação Banco do Brasil, oscila entre entrevistas no estúdio, com dois executivos do Banco do Brasil, e reportagens de campo. Uma delas, feita em São Luís no Maranhão, mostra as mudanças realizadas numa feira livre a partir da atuação articuladora do Banco na região. São vários depoimentos de feirantes, explicando como é sua rotina, um trabalho árduo, iniciado antes do nascer do sol, com grande esforço físico. Todos fazem um relato do tipo antes-e-depois, sendo que o marco da mudança para os feirantes é a entrada em cena do Banco do Brasil, que age como o homem sábio, que explica como agir, dá as condições necessárias para que o herói saia da sua condição inicial, realize sua superação pessoal e desperte em si mesmo o desejo de estender a outros companheiros a mesma trajetória. Uma feirante reitera que a feira será muito melhor quando todos os que nela trabalham puderem passar pelo programa do banco como ela passou. Há, assim, todos os ingredientes clássicos da trajetória do herói como diz Campbell - o momento original, de dificuldade, o convite para a mudança, a decisão de mudar, as dificuldades da jornada, o apoio do sábio, a superação e a vontade de compartilhar o tesouro conquistado com seu povo.

\section{Conclusão}

Como base nestes exemplos, embora muitos pesquisadores que utilizam a narratologia em suas análises da produção jornalística considerem que esta metodologia só é possível para um conjunto seqüencial de notícias, creio ser possível afirmar que o jornalismo contemporâneo reúne todas as características da narrativa clássica.

No caso de programas televisivos que versam sobre responsabilidade social empresarial, a adoção de elementos da narrativa ajuda a despertar o interesse do espectador, individualizando a ação, aproximando universos muitas vezes distantes homem do campo e cidadão de grande metrópole; periferia e centros urbanos; excluídos e incluídos. Também conduz de maneira mais saborosa e mais penetrante a disseminação do conceito da responsabilidade social empresarial como uma prática que ajuda comunidades - e principalmente indivíduos - a resgatarem sua humanidade e sua condição de cidadãos.

A mídia ocupa um lugar especial, senão central, na produção simbólica das sociedades contemporâneas, fornecendo material para que cada indivíduo organize 
sua própria identidade e se articule com as demais individualidades. E Bourdieu ressalta esta centralidade ao dizer que o campo jornalístico age, enquanto campo, isto é, enquanto agente de poder, sobre os outros campos. "As relações entre campo das mídias e outros campos sociais, mediadas através da atividade jornalística, (...) é uma das maiores heranças de Bourdieu”, assegura Ferreira (2005, p.37).

Ao mesmo tempo, Bourdieu ressalta que para que possa haver a imposição do campo jornalístico sobre um outro campo, é necessário que a mídia encontre cumplicidades no outro universo. Há, portanto, uma forte atividade relacional entre os campos, com uma influência desproporcional do campo midiático sobre os demais campos. Isso confere ao campo jornalístico um poder estratégico, hegemônico, que pode tanto reproduzir dominação quanto "trabalhar para difundir armas de defesa" (BOURDIEU, 1998)

Admitindo-se que pressões externas também desempenhem influência sobre o campo jornalístico, a atuação de outros campos pode gerar conteúdo específico, orientações editoriais ou enfoques adotados pela mídia. É possível, portanto, que o surgimento dos programas televisivos sobre responsabilidade social empresarial sejam fruto deste movimento tenso de forças externas e até mesmo de interesses internos do campo jornalístico.

Logo, a construção de heróis pelos programas televisivos de responsabilidade social empresarial é um reflexo desta relação entre o campo jornalístico e outros campos, e colabora na consolidação de práticas de poder que buscam despolitizar o cotidiano, a sociedade, a própria política. A televisão, janela que também é vitrine, é um meio mais que adequado para dar vida e velocidade a este processo. Por ela, se vê a paisagem que muda e reflete a mudança. Por meio dela, se traz a paisagem para dentro da sala de jantar e se passa a acreditar que heróis desfilam emoldurados pela telinha.

Exemplo mais citado do poder da narrativa, Scherazade, nas Mil e Uma Noites, obra clássica da literatura árabe, impedia sua própria morte ao interromper sempre as histórias que contava ao rei Shahryar. Curioso por saber o final da história, o monarca poupava sua vida por mais uma noite. Na noite seguinte, porém, a narradora deixava a história anterior em suspenso e iniciava uma nova. Usando uma 
terminologia jornalística, o que Scherazade fazia era deixar um gancho para que a pauta não morresse. Sempre havia algum elemento novo a ser explorado e que mantinha acessa a curiosidade de quem ouvia. Ao escolher heroicizar os beneficiados pelos programas empresariais de responsabilidade social, os programas televisivos estão em busca de um recurso narrativo para conquistar aquele que olha - para que, ao ver, pela janela da tv, o espectador seja capaz de se reconhecer, e a tela possa virar espelho.

O espetáculo torna a ação representação. Dessa forma, ele retira do campo semântico de 'ação' o que existe de experiência, de vivência, para emprestar-lhe o significado exclusivo de imagem, concedendo a essa ação liberta da experiência condição exemplar de uma agora tonificante,embora desprovida de palavra. Luz, calor, movimento transmissão em massa. A experiência do ver. Do Observar. Se falta à ação representada o respaldo da experiência, esta, por sua vez, passa a ser vinculada ao olhar. $O$ narrador que olha é a contradição e a redenção da palavra na época da imagem. Ele olha para que o seu olhar se recubra de palavra, constituindo uma narrativa. (SANTIAGO, 1989, p. 41)

Como se fosse a voz da mãe contando uma história para ninar o filho, estes programas embalam os sonhos dos espectadores, que seguem creditando às empresas iniciativas e funções que até recentemente pertenciam ao Estado e eram patrimônios públicos das sociedades. Ainda não sabemos o que acontecerá quando se despertar deste sono ou quando Scherazade esgotar seu estoque de heróis.

\section{Referências}

Bakhtin, Mikhail. Estética da Criação Verbal. São Paulo: Martins Fontes, 2003.

Bourdieu, Pierre. Contrafogos. Rio de Janeiro: J. Zahar, 1998

Campbell, Joseph. O herói de mil faces. São Paulo: Pensamento, 1995.

Contursi, Maria Eugenia e Ferro, Fabiola e La narración - usos y teorias. Buenos Aires, Grupo Editorial Norma, 2000 
Costa, Gustavo e Silva, Jorge Lima da. Análise da narrativa jornalística: construção de sentido pela notícia. Trabalho apresentado ao GT Produção de sentido nas mídias, no XII Encontro Anual da Associação Nacional de Programas de Pós-Graduação em Comunicação, Recife, 2003.

Ferreira, Jairo. Mídia, jornalismo e sociedade: a herança normalizada de Bourdieu. In Estudos em Jornalismo Vol. II n ${ }^{0} .11^{\circ}$ semestre de 2005, Insular: Florianópolis, p. 37

Genro Filho, Adelmo. O segredo da pirâmide. - para uma teoria marxista do jornalismo Porto Alegre: Tchê!, 1987.

IBGE. Pesquisa Nacional por Amostra de Domiciliar de 2005, disponível em Pesquisa Nacional por Amostra de Domiciliar de 2005, acesso em 27/11/2006.

Leal, Bruno Souza. Do testemunho à leitura: aspectos da evolução do narrador jornalístico, hoje. 2002. in Biblioteca On-line de Ciências da Comunicação. Disponível em. http://www.bocc.ubi.pt/_esp/autor.php?codautor=697. Acesso em 26/11/2006 . Reflexões sobre o jornalismo como narrativa do real. in Revista Temas Ensaios de Comunicação, 2002.

Motta, Luiz Gonzaga. Para uma antropologia da notícia. In: Revista Brasileira de Ciências da Comunicação. Vol XXV, $\mathrm{n}^{0}{ }_{2}$, julho/dezembro de 2002. p. 1142

Paiva, Raquel. Jornal diário: a estrutura narrativa no terceiro milênio. In Líbero. Ano VI n- ${ }^{0} 12-2003$.

Jornalismo comunitário: uma reinterpretação da mídia (pela construção de um jornalismo pragmático e não dogmático). In Revista Famecos. $\mathrm{N}^{\circ} 30$, agosto de 2006.

Paiva, Raquel e Sodré, Muniz. Sobre o fato e o acontecimento. In Trajectos. Revista de Comunicação, Cultura e Educação. Lisboa, $n^{0} 6$, primavera de 2005

Miranda, R., Pereira, C.A.M. Televisão, as imagens e os sons, no ar, o Brasil. São Paulo: Brasiliense, 1983. 132 p. O nacional e o popular na cultura brasileira.

Santiago, Silviano. O narrador pós-moderno. In Nas malhas da letra - Ensaios. São Paulo: Companhia das Letras, 1989.

Sodré, Muniz. O Monopólio da Fala. Função e linguagem da televisão no Brasil. Petrópolis: Vozes, 2001 